\title{
Comparison of intravenous and intra-articular tranexamic acid in reducing blood loss in primary total knee replacement
}

\author{
Primer total diz replasmanında kan kaybını azaltmada intravenöz ve \\ intraartiküler traneksamik asidin karşılaştırılması
}

\author{
Marek Lacko, MD, PhD, Robert Cellar, MD, PhD., Daniela Schreierova, MD, Gabriel Vasko, Prof, PhD. \\ Department of Orthopedics and Traumatology of Locomotors Apparatus, Medical Faculty of Pavol Jozef Šafárik University and \\ University Hospital of L. Pasteur, Kosice, Slovakia
}

\begin{abstract}
Objectives: This study aims to compare the efficacy and safety of intra-articular tranexamic acid (TA) versus intravenous (IV) TA in the reduction of perioperative blood loss and the degree of early postoperative complications associated with primary unilateral cemented total knee replacement.
\end{abstract}

Patients and methods: This prospective randomized study included 90 patients (36 males, 54 females; mean age 68.7 years; range 47 to 82 years) with knee osteoarthritis undergoing a unilateral cemented total knee replacement. Patients were randomized into three groups: group 1 received TA intravenously (dose $10 \mathrm{mg} / \mathrm{kg}$ ) 20 minutes preoperatively and three hours after first dose, group 2 received TA (dose $3 \mathrm{~g}$ ) locally (intra-articular) into surgical site, and group 3 did not receive TA. We measured perioperative blood loss, volume of drained blood in 24 hours postoperatively, overall blood loss, decrease in hemoglobin and hematocrit levels, and amount of blood transfusion.

Results: There were no differences between the groups in terms of patient preoperative demographics. Local or IV administration of TA significantly reduced the number of blood transfusions and blood losses in drainage. Intravenous application of TA was associated with statistically significantly higher hemoglobin and hematocrit levels and lower overall postoperative blood losses. No serious complications were observed in any of the groups.

Conclusion: Intra-articular TA was equally effective as IV regimen in reducing the number of blood transfusions. However, IV administration of TA was associated with overall lower blood loss. Our results showed that IV administration of TA during total knee replacement is superior compared to intra-articular administration of TA.

Keywords: Arthroplasty; knee; replacement; tranexamic acid.
ÖZ

Amaç: $\mathrm{Bu}$ çalışmada primer tek taraflı çimentolu total diz ameliyatı sırasında kan kaybını ve ameliyat sonrası erken komplikasyonların derecesini azaltmada intraartiküler traneksamik asit (TA) ve intravenöz (IV) TA'nın etkinliği ve güvenilirliği karşılaştırıldı.

Hastalar ve yöntemler: $\mathrm{Bu}$ prospektif randomize çalışmaya diz osteoartriti olup tek taraflı çimentolu total diz replasmanı ameliyatı geçiren 90 hasta (36 erkek, 54 kadın; ort. yaş 68,7 yıl; dağılım 47-82 yıl) dahil edildi. Hastalar üç gruba randomize edildi: grup 1'e ameliyattan 20 dakika önce ve ilk dozdan üç saat sonra İV yolla TA (doz $10 \mathrm{mg} / \mathrm{kg}$ ) verildi, grup 2'ye cerrahi alana lokal olarak (intraartiküler) TA (doz $3 \mathrm{~g}$ ) verildi ve grup 3'e TA verilmedi. Ameliyat sırasındaki kan kaybı, ameliyat sonrası 24 saatte boşaltılan kan miktarı, toplam kan kaybı, hemoglobin ve hematokrit düzeylerindeki azalma ve kan transfüzyonu miktarı ölçüldü.

Bulgular: Hastaların ameliyat öncesi demografik verilerinde gruplar arasında farklılık yoktu. Traneksamik asitin lokal veya IV uygulaması kan transfüzyonu sayısını ve drenajdaki kan kaybını anlamlı şekilde azalttı. Traneksamik asitin IV uygulaması istatistiksel olarak anlamlı daha yüksek hemoglobin ve hematokrit düzeyleri ve daha düşük ameliyat sonrası toplam kan kaybı ile ilişkiliydi. Grupların hiçbirinde ciddi komplikasyon gözlemlenmedi.

Sonuç: Kan transfüzyonu sayısını azaltmada intraartiküler TA İV rejim kadar etkili idi. Ancak TA'nın IV uygulaması daha düşük toplam kan kaybı ile ilişkiliydi. Bulgularımız total diz replasmanı sırasında TA'nın IV uygulamasının intraartiküler uygulamaya göre daha üstün olduğunu gösterdi.

Anahtar sözcükler: Artroplasti; diz; replasman; traneksamik asit.

- Received: February 02, 2017 Accepted: March 06, 2017

- Correspondence: Marek Lacko, MD, PhD. Department of Orthopedics and Traumatology of Locomotors Apparatus, Medical Faculty of P.J. Safarik University and University Hospital of L. Pasteur, Trieda SNP 1, 04001 Kosice, Slovakia. Tel: +42 1556403535 e-mail: marek.lacko@upjs.sk 
Total knee arthroplasty is associated with major blood loss. According to the reports in the literature, 10 to $70 \%$ of patients who undergo this operation receive blood transfusions (BTs). ${ }^{[1,2]}$ Allogenic BTs are associated with risks such as acute and delayed transfusion reaction, transmission of infectious diseases, inhibition of immune system and volume overload of the heart. Blood transfusions also increase the cost of hospitalization. ${ }^{[3]}$

There are several methods available to reduce perioperative blood loss and thus the need of BT, e.g. preoperative administration of erythropoietin and iron supplements, normovolemic hemodilution, controlled hypotension, tourniquet use, platelet rich plasma, and fibrin gel or pharmacological measures. Pharmacological measures aimed at the reduction of perioperative blood losses include anti-fibrinolytic drugs, e.g. aprotinin, epsilon-aminocaproic acid, and tranexamic acid (TA). ${ }^{[4]}$ Tranexamic acid is a synthetic agent with antifibrinolytic effect-inhibiting the fibrinolytic activity of plasmin. The inhibition is provided by TA forming a complex with plasminogen, persisting even when it is converted to plasmin. ${ }^{[5]}$

The first documented use of TA with an objective to reduce blood losses during total knee replacement was in $1995 .^{[6]}$ Since that period, several clinical studies have confirmed a positive effect of intravenous (IV) TA administration on the reduction of blood loss associated with joint replacement surgery. With certain concomitant disorders, such as renal insufficiency, cardiovascular disease or neurovascular disease, there is still concern about the increased risk of thromboembolic events following IV administration of TA. To minimize the systemic effects of TA, the intra-articular administration of TA, i.e. local administration in the surgical wound during joint replacement, is becoming more and more popular in recent years. At present, there is no consensus related to the optimum method of administration and dosage of TA during total joint replacement.

In this study, we aimed to compare the efficacy and safety of intra-articular TA versus IV TA in the reduction of perioperative blood loss and the degree of early postoperative complications associated with primary unilateral cemented total knee replacement.

\section{PATIENTS AND METHODS}

This prospective randomized study included 90 patients (36 males, 54 females; mean age 68.7 years; range 47 to 82 years) who underwent unilateral cemented total knee replacement at University Hospital of L. Pasteur in Kosice for primary or secondary osteoarthritis between February 2014 and May 2015. The patients were randomized into three groups according to the method of TA administration, with 30 patients in each: group 1 received IV TA, group 2 received local (intra-articular) TA into surgical wound, and group 3 received no TA. We used online statistical computing web programming (www.graphpad.com/quickcalcs) to randomize the subjects into groups with equal sample size. ${ }^{[7]}$ The study protocol was approved by the University Hospital of L. Pasteur in Kosice Ethics Committee. A written informed consent was obtained from each patient. The study was conducted in accordance with the principles of the Declaration of Helsinki.

Intravenous application included two administrations of TA at the dose of $10 \mathrm{mg} / \mathrm{kg}$. The first dose was administered 20 minutes prior to incision and the second dose was administered three hours after the first dose. Local (intra-articular) administration involved the application of $3 \mathrm{~g}$ of TA in $50 \mathrm{~mL}$ of saline, applied directly into surgical wound following the cementing of the implant. Subsequently, the wound was not flushed anymore and after five minutes of exposure to TA, the wound was sutured. The dosage of TA was derived on the basis of protocols presented by published reports evaluating the efficacy of TA in the reduction of blood losses following total knee replacement. ${ }^{[8-11]}$

All operations were performed under spinal anesthesia, using the same surgical technique (midline skin incision, medial parapatellar capsulotomy). Tourniquet was used only during cementing. Same type of cemented posterior cruciate ligamentretaining knee replacement was used in all patients (Columbus-Aesculap, B. Braun, Tuttlingen, Germany). Intramedullary aiming was used for femoral resection and extramedullary aiming was used for tibial resection. Evacuation drainage was turned on to active suction after four hours from the finishing of operation and left on for 24 hours. Antibiotic prevention and prevention of thromboembolism using left ventricular mass by height was the same in all patients.

The basic characteristics of individual groups were based on the expression of the mean age, male to female ratio, body mass index, classification of perioperative risk according to the American Society of Anesthesiologists (ASA), and mean preoperative hemoglobin and hematocrit values.

We observed perioperative blood loss and blood loss to drainage for 24 hours postoperatively, and total perioperative losses were thus calculated 
(sum of perioperative losses and blood losses in drainage after 24 hours). We also observed the decrease of hemoglobin and hematocrit levels compared to preoperative values and total number of BT units used. Blood transfusion was indicated in patients with hemoglobin decrease under $8 \mathrm{~g} / \mathrm{dL}$, or under $9 \mathrm{~g} / \mathrm{dL}$, if the patient had simultaneous signs of postoperative anemia. Blood count was assessed at six hours and then at two and five days postoperatively.

We observed the time of operation and the occurrence of postoperative complications in the period of three months after total knee replacement. In case of clinical signs of thrombosis, ultrasound of the venous system of lower limbs was indicated.

We excluded patients with known TA allergy, history of thromboembolism, cerebrovascular accidents, severe liver and kidney disease or blood clotting disorders.

\section{Statistical analysis}

Simple sorting scatter analysis has been carried out to validate the hypothesis of equality of the means of individual parameters. Tukey-Kramer test was used for comparison between groups. Statistical significance was defined at a significance level of $\mathrm{p}<0.05$.

\section{RESULTS}

There was no statistically significant difference between groups with respect to the mean age, body mass index, ASA level, or preoperative levels of hemoglobin and hematocrit (Table I).

Blood losses during implantation of total knee replacement were similar in all groups with no statistically significant difference. Blood loss in Redon drainage after 24 hours was significantly higher in group 3 compared to groups 1 and 2. Comparison of blood losses between groups 1 and 2 revealed no statistically significant difference.

Assessment of total blood loss, i.e. sum of perioperative loss and blood loss in Redon drainage after 24 hours, showed the lowest values in group 1 . Compared to group 3, the difference was statistically significant. The difference in blood loss between group 2 and group 3 as well as between groups 1 and 2 did not reach statistical significance (Figure 1).

Mean number of administered BT units was highest in group $3(0.7 \pm 1$ BT unit). Compared to groups $2(0.2 \pm 0.55 \mathrm{BT}$ unit) and $1(0.07 \pm 0.25 \mathrm{BT}$ unit), the difference was statistically significant (Figure 2). Group 1 required the lowest number BTs overall (two BT units in two patients), however, compared to group 2 (seven BT units in four patients), the difference failed to reach statistical significance. All BT units in groups 1 and 2 were administered on the basis of results of blood tests performed on the postoperative second day. In group 3, we administered 21 BT units in 15 patients. One patient received $\mathrm{BT}$ unit at postoperative sixth hour. A total of 14 patients received BT units at postoperative second day.

Mean hemoglobin and hematocrit levels at postoperative sixth hour, and second and fifth days were highest in group 1 , with statistically significant difference compared to group 3 (Figures 3 and 4). We did not include in the comparison the results of hemoglobin and hematocrit levels in patients who received BT. All patients were included in assessment at postoperative sixth hour. We excluded one patient

\section{TABLE}

Preoperative demographics

\begin{tabular}{|c|c|c|c|c|c|c|c|}
\hline \multirow[t]{2}{*}{ Demographics } & \multicolumn{2}{|c|}{ Group $1(\mathrm{n}=30)$} & \multicolumn{2}{|c|}{ Group $2(\mathrm{n}=30)$} & \multicolumn{2}{|c|}{ Group $3(\mathrm{n}=30)$} & \multirow[b]{2}{*}{$p$} \\
\hline & $\mathrm{n}$ & Mean $\pm S D$ & $\mathrm{n}$ & Mean $\pm S D$ & $\mathrm{n}$ & Mean $\pm S D$ & \\
\hline Age (year) & & $68.4 \pm 7.2$ & & $67.5 \pm 7.7$ & & $70 \pm 6.1$ & NS \\
\hline Gender & & & & & & & NS \\
\hline Male & 12 & & 13 & & 11 & & \\
\hline Female & 18 & & 17 & & 19 & & \\
\hline Body mass index $\left(\mathrm{kg} / \mathrm{m}^{2}\right)$ & & $31.1 \pm 4.7$ & & $31.9 \pm 4.7$ & & $31.5 \pm 4.8$ & NS \\
\hline American Society of Anesthesiologists grade & & $2.5 \pm 0.6$ & & $2.3 \pm 0.5$ & & $2.6 \pm 0.6$ & NS \\
\hline Preoperative hemoglobin (g/dL) & & $13.9 \pm 1.2$ & & $13.8 \pm 0.9$ & & $13.6 \pm 1.4$ & NS \\
\hline Preoperative hematocrit & & $0.4 \pm 0.0$ & & $0.4 \pm 0.0$ & & $0.4 \pm 0.0$ & NS \\
\hline
\end{tabular}

Group 1: Group of patients with intravenous administration of tranexamic acid; Group 2: Group of patients with intra-articular administration of tranexamic acid; Group 3: Group of patients without administration of tranexamic acid; ASA: American Society of Anesthesiologists; NS: Not significant; SD: Standard deviation; $p$ value was calculated using Tukey-Kramer test. 


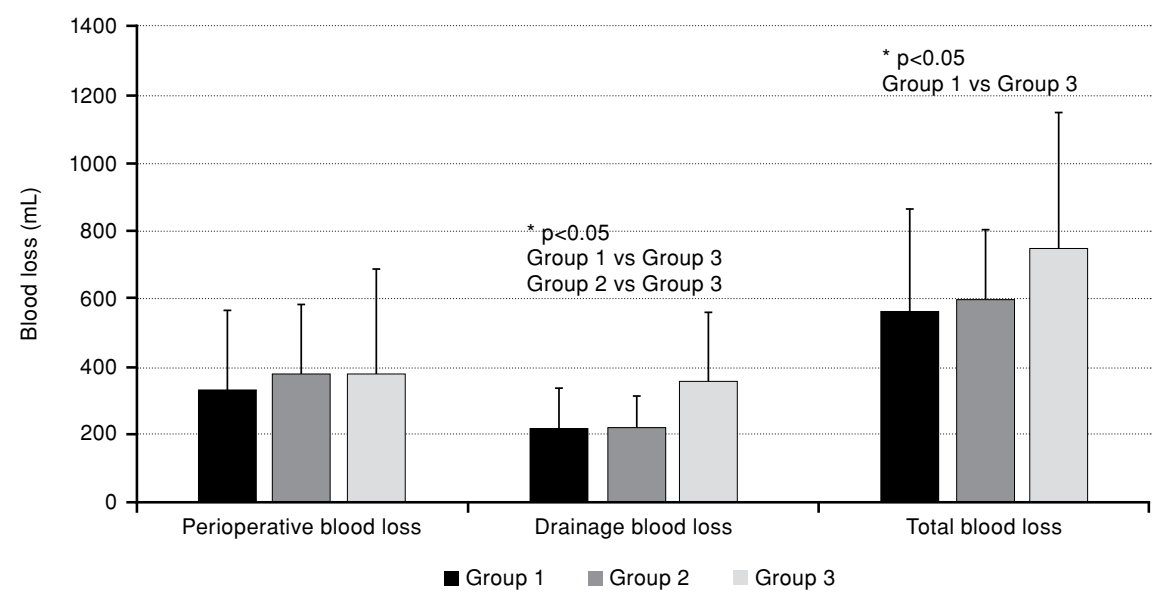

Figure 1. Total blood loss (sum of perioperative blood loss and blood loss in Redon drainage after 24 hours). Asterisks indicate values that were significantly different between groups. Group 1: Group of patients with intravenous administration of tranexamic acid; Group 2: Group of patients with intra-articular administration of tranexamic acid; Group 3: Group of patients without administration of tranexamic acid.

from group 1, who was given BT on the postoperative second day. Other 14 patients in group 3, two patients in group 1 and four patients in group 3 with BTs were not included in the comparison of results at postoperative fifth day.

Longest duration of operation was observed in group 2 (82.2 \pm 16.9 minutes), with statistically significant difference compared to the duration of operation in group $1 \quad(71.7 \pm 14.6$ minutes $)(\mathrm{p}<0.05)$. Mean duration of operation in group $3(75.7 \pm 15.2$ minutes) was not statistically significantly different in comparison to groups 1 and 2 .

We did not observe any significant postoperative complications in the three-month follow-up period.
Ultrasound of the venous system of the lower limbs was indicated in one patient in group 1 and in one patient in group 3 due to edema of the lower part of the leg. The ultrasound evaluation did not confirm the thrombosis of the leg.

\section{DISCUSSION}

The results of our study confirmed that local administration of TA at the dose of $3 \mathrm{~g}$, as well as IV administration of TA in two doses of $10 \mathrm{mg} / \mathrm{kg}$, significantly reduces the number of administered BTs and blood losses in evacuation drainage following the implantation of cemented total knee replacements. Intravenous application of TA was associated with statistically significantly lower overall postoperative

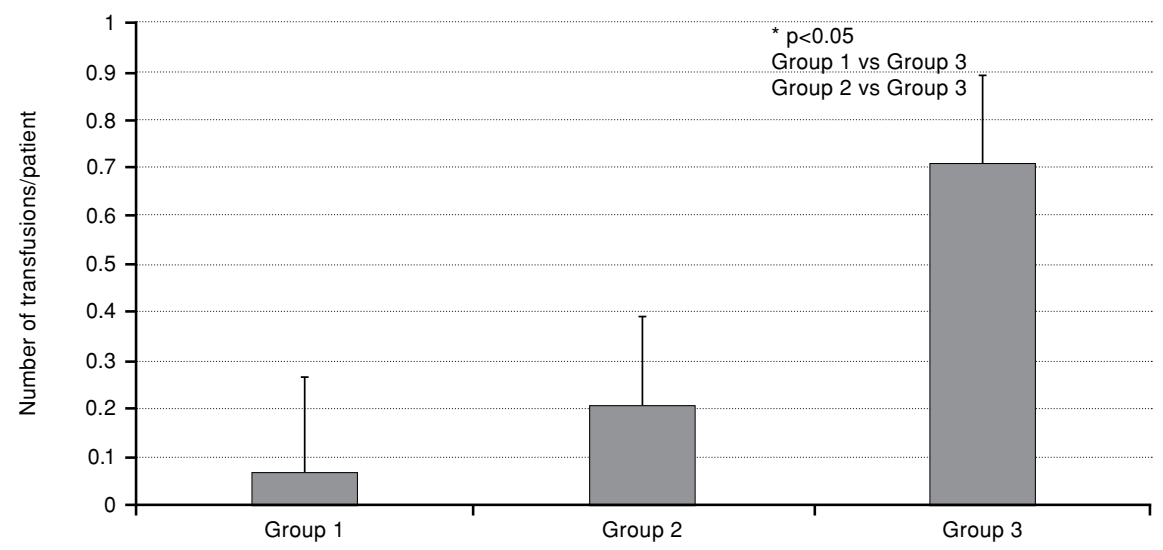

Figure 2. Mean number of administered blood transfusion units. Asterisks indicate values that were significantly different between groups. Group 1: Group of patients with intravenous administration of tranexamic acid; Group 2: Group of patients with intra-articular administration of tranexamic acid; Group 3: Group of patients without administration of tranexamic acid. 


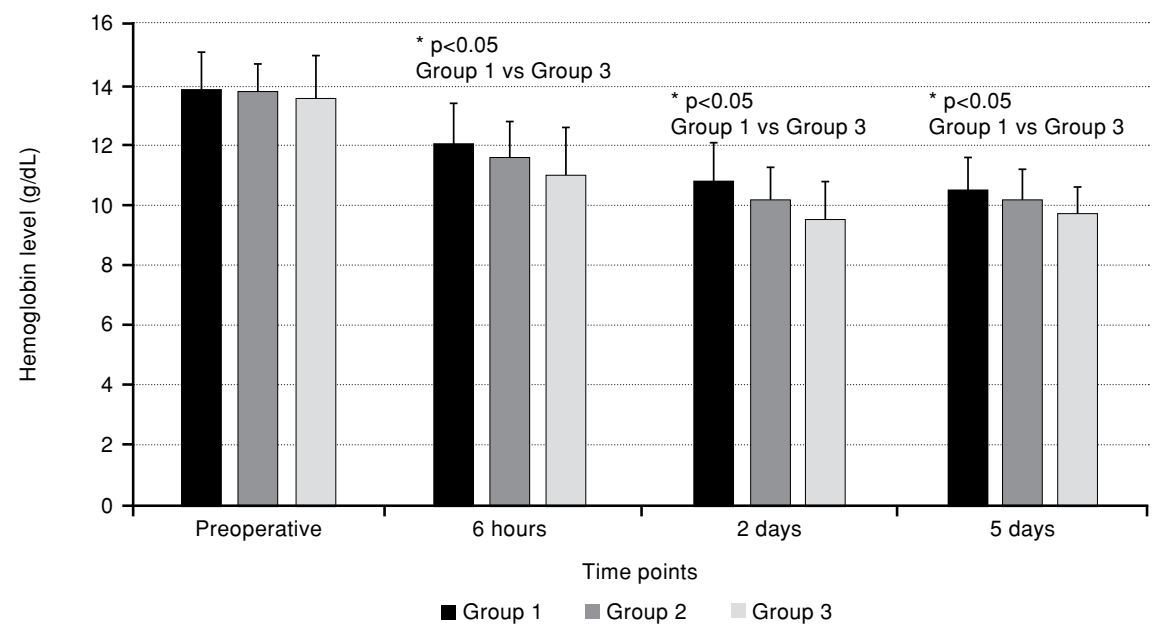

Figure 3. Mean hemoglobin levels. 6 hours: Value at postoperative sixth hour; 2 days: Value at postoperative second day; 5 days: Value at postoperative fifth day. Patients who received blood transfusions were excluded; asterisks indicate values that were significantly different between groups; Group 1: Group of patients with intravenous administration of tranexamic acid; Group 2: Group of patients with intra-articular administration of tranexamic acid; Group 3: Group of patients without administration of tranexamic acid.

blood losses compared to the group that did not receive TA, and the group that received local TA.

Total knee replacement is associated with significant blood losses. According to various sources, the blood loss amounts 400 to $2000 \mathrm{~mL}$ of blood on the average. ${ }^{[12]}$ Surgical trauma leads to the activation of fibrinolysis, even more increasing the perioperative blood losses. ${ }^{[13]}$ Tranexamic acid inhibits fibrinolysis, thus reducing postoperative blood losses. Tranexamic acid can be used by various means-pre-, peri- or postoperatively, or by a combination of these three possible methods of administration. Following the IV administration, TA is distributed in intracellular and extracellular compartments, quickly diffusing into synovial fluid. Biological half-time for TA is 3 hours, $90 \%$ of the administered TA is excreted through kidneys within 24 hours. ${ }^{[14]}$

Recent meta-analyses confirm that IV administration of TA reduces perioperative blood losses involved in theimplantation of knee replacement, without increased incidence of thromboembolic events or infectious complications..$^{[15-17]}$ Nevertheless, with several accompanying concomitant disorders, such as renal insufficiency, cardiovascular disorders,

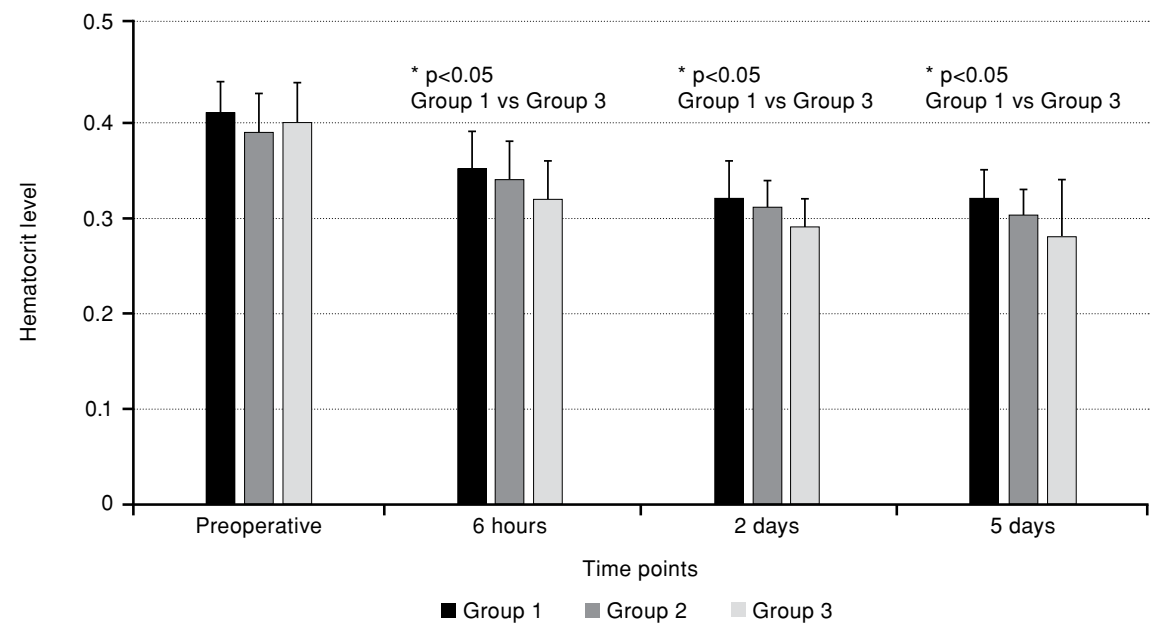

Figure 4. Mean hematocrit levels. 6 hours: Value at postoperative sixth hour; 2 days: Value at postoperative second day; 5 days: Value at postoperative fifth day. Patients who received blood transfusions were excluded; asterisks indicate values that were significantly different between groups. Group 1: Group of patients with intravenous administration of tranexamic acid; Group 2: Group of patients with intra-articular administration of tranexamic acid; Group 3: Group of patients without administration of tranexamic acid. 
neurovascular disorders or patients with a history of deep venous thrombosis, history of myocardial infarction, cerebrovascular accident or hormonal substitution therapy, there is still concern about increased risk of thromboembolic events following the IV administration of TA. Intra-articular administration of TA directly in surgical wound is increasingly used in total joint replacement surgery.

Intra-articular administration-either in the form of "flushing" of surgical wound using TA solution or application of TA through drain tube into sutured surgical wound is based on simple application, higher concentrations at the point of bleeding with minimization of systemic effects. Meta-analysis by Alshryd et al., ${ }^{[18]}$ including nine randomized controlled studies, has reported significant reduction of blood losses involved in the intra-articular administration of TA during implantation of total knee replacements, without any increase in the risk of incidence of thromboembolic disease. Similar conclusions have been obtained from meta-analysis by Zhao-yo et al. ${ }^{[19]}$

At present, we do not have sufficient information to determine which form of TA administration most efficiently reduces blood losses during implantation of total knee replacements. Studies that directly compare the efficacy of local and IV form of TA administration bring conflicting conclusions related to the efficacy of reduction of blood loss. While the conclusions of studies by Hamlin et al. ${ }^{[20]}$ and Seoa et al. ${ }^{[21]}$ have pointed out the higher efficacy of intra-articular administration of TA, Sarzaeema et al ${ }^{[22]}$ have found significantly lower incidence of administered BTs in patients with IV administration of TA. The results of our study confirm the efficacy of both forms of TA administration to reduce the number of required BTs. Relatively high rate of BTs in the group that did not receive TA $(50 \%$; 15 of 30 patients received BTs) corresponds to average consumption of BTs in our department and is consistent with the literature data. The prevalence of BTs after total knee arthroplasty has been reported to be between $11 \%$ to $69 \%$. $^{[23,24]}$

However, overall postoperative losses were significantly lower in patients with IV administration of TA (200 mL of blood less compared to group that did not receive TA). Also, the local means of TA administration was associated with lower overall losses, by $150 \mathrm{~mL}$ of blood. However, this difference failed to reach statistical significance, despite the fact that local administration was associated with significantly lower number of BTs compared to the group that did not receive TA. Similarly, when assessing the values of hemoglobin and hematocrit levels in the course of the postoperative five days, we found significantly higher values of hemoglobin and hematocrit levels in the group of patients who received TA intravenously. To maintain the same conditions for evaluations of hemoglobin and hematocrit levels, we excluded results of patients who received BT.

To our knowledge, no comparative study identified any increased risk of thromboembolic or infectious complications following TA administration. The safety of both TA administration techniques has also been confirmed by the results of our study.

In the available literature, we have found a single meta-analysis that evaluated the results of six randomized controlled and cross-sectional studies comparing IV and local administration of TA in association with total knee replacements. ${ }^{[25]}$ The authors did not find any difference in the degree of postoperative blood loss, number of administered BTs and in the incidence of thromboembolic complications.

Certain discrepancy between the results of individual studies comparing local and intravenous form of TA administration stems from several factorsdifference in surgical technique (intramedullary, extramedullary aiming of bone resection, use of computer navigation), different timing of TA administration and TA dosing, tourniquet use (during entire operation or only during cementing), use of postoperative evacuation drainage, different indication criteria for application of BTs, etc. At our department, we use tourniquet only during cementing of the implants; this enables us to better control bleeding in the surgical wound, while it may also increase overall blood losses despite the administration of TA. We believe that gentle surgical technique and wound drainage based on starting the active evacuation only at postoperative fourth hour is also important in the control of bleeding.

Extended duration of operation in the group of patients with local administration of TA resulted from the process of preparation and application of TA that was left to "act" in the surgical wound for five minutes. As no postoperative complications have been observed, this prolongation of the duration of operation was clinically insignificant.

Certain limitations of our study result from our patient population, operated by three different surgeons. Despite the fact that all were experienced surgeons with extensive experience in the area of knee replacement surgery, individual differences in surgical technique may have had an effect on perioperative blood losses. On the other hand, there 
was the advantage of having the control group of patients who did not receive any TA. This enabled us to confirm the efficacy of TA administration (IV and local) on the reduction of blood losses.

In conclusion, despite the results of the published clinical studies assessing the positive effects of TA on the reduction of blood losses following total knee replacement surgery, the ideal method of administration and dosage of TA remain to be determined by additional clinical studies and expert discussions. Our study confirmed the current knowledge related to the safety of the application of TA in association with cemented total knee replacements, either through intra-articular or IV application. In postoperative course, both methods of TA administration techniques were able to significantly reduce the number of BTs. However, IV administration of TA was associated with overall lower blood loss and higher hemoglobin and hematocrit values. The above results showed that the IV administration of TA during total knee replacement is superior compared to intra-articular administration of TA.

\section{Declaration of conflicting interests}

The authors declared no conflicts of interest with respect to the authorship and/or publication of this article.

\section{Funding}

The authors received no financial support for the research and/or authorship of this article.

\section{REFERENCES}

1. Bierbaum BE, Callaghan JJ, Galante JO, Rubash HE, Tooms RE, Welch RB. An analysis of blood management in patients having a total hip or knee arthroplasty. J Bone Joint Surg [Am] 1999;81:2-10.

2. Noticewala MS, Nyce JD, Wang W, Geller JA, Macaulay W. Predicting need for allogeneic transfusion after total knee arthroplasty. J Arthroplasty 2012;27:961-7.

3. Aydın BK, Durgut F, Erkoçak ÖF, Acar MA. Other benefits of intra-articular injection of tranexamic acid in primary total knee arthroplasty apart from reducing blood transfusion rates. Eklem Hastalik Cerrahisi 2017;28:25-9.

4. Eubanks JD. Antifibrinolytics in major orthopaedic surgery. J Am Acad Orthop Surg 2010;18:132-8.

5. Dunn CJ, Goa KL. Tranexamic acid: a review of its use in surgery and other indications. Drugs 1999;57:1005-32.

6. Benoni G, Carlsson A, Petersson C, Fredin H. Does tranexamic acid reduce blood loss in knee arthroplasty? Am J Knee Surg 1995;8:88-92.

7. Suresh K. An overview of randomization techniques: An unbiased assessment of outcome in clinical research. J Hum Reprod Sci 2011;4:8-11.

8. Soni A, Saini R, Gulati A, Paul R, Bhatty S, Rajoli SR. Comparison between intravenous and intra-articular regimens of tranexamic acid in reducing blood loss during total knee arthroplasty. J Arthroplasty 2014;29:1525-7.
9. Gomez-Barrena E, Ortega-Andreu M, Padilla-Eguiluz NG, Pérez-Chrzanowska H, Figueredo-Zalve R. Topical intraarticular compared with intravenous tranexamic acid to reduce blood loss in primary total knee replacement: a double-blind, randomized, controlled, noninferiority clinical trial. J Bone Joint Surg [Am] 2014;96:1937-44.

10. Georgiadis AG, Muh SJ, Silverton CD, Weir RM, Laker MW. A prospective double-blind placebo controlled trial of topical tranexamic acid in total knee arthroplasty. J Arthroplasty 2013;28:78-82.

11. Wong J, Abrishami A, El Beheiry H, Mahomed NN, Roderick Davey J, Gandhi R, et al. Topical application of tranexamic acid reduces postoperative blood loss in total knee arthroplasty: a randomized, controlled trial. J Bone Joint Surg [Am] 2010;92:2503-13.

12. Sehat KR, Evans R, Newman JH. How much blood is really lost in total knee arthroplasty?. Correct blood loss management should take hidden loss into account. Knee 2000;7:151-5.

13. Kambayashi J, Sakon M, Yokota M, Shiba E, Kawasaki T, Mori T. Activation of coagulation and fibrinolysis during surgery, analyzed by molecular markers. Thromb Res 1990;60:157-67.

14. McCormack PL. Tranexamic acid: a review of its use in the treatment of hyperfibrinolysis. Drugs 2012;72:585-617.

15. Alshryda S, Sarda P, Sukeik M, Nargol A, Blenkinsopp J, Mason JM. Tranexamic acid in total knee replacement: a systematic review and meta-analysis. J Bone Joint Surg [Br] 2011;93:1577-85.

16. Kagoma YK, Crowther MA, Douketis J, Bhandari M, Eikelboom J, Lim W. Use of antifibrinolytic therapy to reduce transfusion in patients undergoing orthopedic surgery: a systematic review of randomized trials. Thromb Res 2009;123:687-96.

17. Yang ZG, Chen WP, Wu LD. Effectiveness and safety of tranexamic acid in reducing blood loss in total knee arthroplasty: a meta-analysis. J Bone Joint Surg [Am] 2012;94:1153-9.

18. Alshryda S, Sukeik M, Sarda P, Blenkinsopp J, Haddad FS, Mason JM. A systematic review and meta-analysis of the topical administration of tranexamic acid in total hip and knee replacement. Bone Joint J 2014;96:1005-15.

19. Zhao-Yu C, Yan G, Wei C, Yuejv L, Ying-Ze Z. Reduced blood loss after intra-articular tranexamic acid injection during total knee arthroplasty: a meta-analysis of the literature. Knee Surg Sports Traumatol Arthrosc 2014;22:3181-90.

20. Hamlin BR, DiGioia AM, Plakseychuk AY, Levison TJ. Topical versus intravenous tranexamic acid in total knee arthroplasty. J Arthroplasty 2015;30:384-6.

21. Seo JG, Moon YW, Park SH, Kim SM, Ko KR. The comparative efficacies of intra-articular and IV tranexamic acid for reducing blood loss during total knee arthroplasty. Knee Surg Sports Traumatol Arthrosc 2013;21:1869-74.

22. Sarzaeem MM, Razi M, Kazemian G, Moghaddam ME, Rasi AM, Karimi M. Comparing efficacy of three methods of tranexamic acid administration in reducing hemoglobin drop following total knee arthroplasty. J Arthroplasty 2014;29:1521-4.

23. Carling MS, Jeppsson A, Eriksson BI, Brisby $H$. Transfusions and blood loss in total hip and knee arthroplasty: a prospective observational study. J Orthop Surg Res 2015;10:48. 
24. Rosencher N, Kerkkamp HE, Macheras G, Munuera LM, Menichella G, Barton DM, et al. Orthopedic Surgery Transfusion Hemoglobin European Overview (OSTHEO) study: blood management in elective knee and hip arthroplasty in Europe. Transfusion 2003;43:459-69.

25. Wang H, Shen B, Zeng Y. Comparison of topical versus intravenous tranexamic acid in primary total knee arthroplasty: a meta-analysis of randomized controlled and prospective cohort trials. Knee 2014;21:987-93. 